\title{
Nursing assessment of post-operative pain in patients undergoing general (thoracic) surgery
}

\author{
Bakalis $\mathrm{N}^{1 *}$, Vescio $\mathrm{G}^{4}$, Chounti $\mathrm{M}^{2}$, Michalopoulou $\mathrm{E}^{3}$, Kiekkas $\mathrm{P}^{1}$, Rizzuto $\mathrm{A}^{4}$, Papandrea $\mathrm{M}^{5}$, Sena G ${ }^{5}$, Barberio $\mathrm{A}^{5}$, Tiesi $\mathrm{V}^{5}$, Gambardella \\ $\mathrm{D}^{5}$, Gallo G ${ }^{5}$, Curro G ${ }^{6}$, Ammendola $\mathrm{M}^{7}$, De Franciscis $\mathrm{S}^{4}$ and Filiotis $\mathrm{N}^{4}$ \\ ${ }^{1}$ Department of Nursing, Technological Educational Institute of Western Greece, Patras, Greece \\ ${ }^{2}$ Technological Educational Institute of Western Greece, Patras, Greece \\ ${ }^{3}$ Department of Nursing, Technological Educational Institute of Western Greece, Department of Nursing, Patras, Greece \\ ${ }^{4}$ Department of Medicine and Surgical Sciences, University of Magna Graecia, Catanzaro, Italy \\ ${ }^{5}$ Surgical Department, General University Hospital of Catanzaro, Italy \\ ${ }^{6}$ Department of Health Sciences, University of Magna Graecia, Catanzaro, Italy \\ ${ }^{7}$ Department of Medicine and Surgical Sciences, University of Magna Graecia, Catanzaro, Italy
}

\begin{abstract}
Introduction: Postoperative pain is an unpleasant experience for patients after thoracic surgery. It is known that these types of surgical procedures cause high intensity of pain. Proper nursing assessment of the patients' pain is critical as for the right decision to be made in terms of offering quality care and support.

Aim: The aim of this study was the evaluation of postoperative pain experienced by patients following thoracic surgery and the correlation with demographic characteristics as well as other factors.

Methodology: The McGill questionnaire (long form) was used and statistical analysis was performed with SPSS 21. The sample included ( $\mathrm{n}=30)$ patients that had thoracic surgery. The study took place in a thoracic surgical department of a hospital in Athens, Greece.

Results: Patients mean age was 59 years, $73 \%$ had higher education qualifications, $66.7 \%$ were male and $33.3 \%$ were female. In addition, $40 \%$ were from islands, $40 \%$ urban and $20 \%$ suburban areas of Greece. The majority of the sample (70\%) were smokers, while $43 \%$ were diagnosed with lung cancer. The vast majority of the sample $93.3 \%$ had a close chest drain in situ postoperatively, while thoracotomy was performed on $56.66 \%$ of the participants. Pain at the incision site was reported by $43.3 \%$, while $90 \%$ of the sample reported absence of external pain and $70 \%$ felt relieved with the use of medication. The vast majority of the sample (90\%) had undergone surgery with general anesthesia and reported less pain than patients who had local analgesia. Interestingly, the progression of the intensity and type of pain experienced by the patient depends on the recovery days after surgery (a reduction was observed the 5th and 6th day), as it illustrated a gradual decrease up to the day the patient was discharged.
\end{abstract}

Conclusion: This study is original in the international literature. There is no recognized tool to measure postoperative pain experienced by patients who have had thoracic surgery. Based on the results of this study we emphasize the necessity for the design and implementation of an appropriate postoperative assessment questionnaire for these patients.

\section{Introduction}

The definitions that have been given for pain by health care professionals are diverse and each has its own restrictions. In 1986, the World Health Organization (WHO) adopted the definition of pain as it was formulated by Merskey et al. [1] where they declared that it is an unpleasant sensory and emotional experience that is associated with actual or potential tissue damage or described in terms of such damage.

The most up-to-date scientific studies on pain, perception and healing began in the 20th century. At that time, new theories developed, and new therapeutic protocols were implemented. However, even today, human pain has not been properly assessed and this is due to barriers within the health care system, nurses, doctors, patients and their support system. As a result, the above barriers directly contribute to a failed assessment of pain, resulting in a total failure to take the necessary measures [2].
The nurses' goal is to manage and successfully deal with pain as it is a key element in post-operative care for each patient [3]. Appropriate analgesic drugs are administered as well as continuous monitoring and assessment of their condition is carried out, thus allowing the patient to soon return to their daily activities.

\section{Types and characteristics of pain}

Pain can be classified as chronic or acute, quantitatively: as mild, moderate, severe or very severe, physiologically: as physical, visceral or neuropathic and causative: as pathological or psychogenic [4].

${ }^{*}$ Correspondence to: Bakalis NA, Megalou Alexandrou, Koukouli, Patras, Greece, Tel: +30-6938053217; Fax: +30-2610-369175; E-mail: nikosbakalis@teiwest.gr

Key words: pain assessment, thoracic surgery, quantitative research, pain assessment, pain management

Received: December 14, 2018; Accepted: December 22, 2018; Published: December 26, 2018 
According to Woolf and Salter [5] who attempt to analyze the pathophysiology of pain, they explain how pain activates the sensory system and set the distinction of pain into normal and pathological. Normal pain is classified as mechanical, chemical and thermal stimuli that follow the process response. As for pathological pain, they explain that the inflammatory response causes tissues damage of the nervous system, which is classified as inflammatory and neuropathic pain.

\section{Postoperative pain}

Post-operative pain is a specific type of pain that occurs after surgical procedures. It is one of the bodies' most important defense mechanisms as it signals the diseased state [6].

Postoperatively intense pain induces immunosuppression and is observed in decreased laboratory findings of leukocytosis with lymphopenia and suppression of the reticulo-endothelial system [7]. The patient is strongly predisposed to infections and it is within the role of the nurse to protect the patient and his family from such a challenge. The patient's cardiovascular system may experience a variety of symptoms due to sympathetic stimulation. Symptoms such as tachycardia, hypertension, increased cardiac output and the myocardium's increased need of oxygen, are among the most common [8].

The respiratory and cardiovascular systems are that exhibit most of the complications after thoracic surgery. Due to intense post-operative pain, patients tend to reduce respiratory movements, and chest mobility [9]. At the same time, inadequate ability to cough results in the retention of secretions, the occurrence of atelectasis, and the possible onset of a respiratory infection [10].

During surgery, anesthetic drugs that are used cause side effects affecting the digestive and urinary system. Often, the patient may experience postoperative ileus, nausea and vomiting [11], while from the urinary system symptoms such as difficulty in urination or even retention [12] (Figures 1 and 2).

\section{Pain evaluation tools}

There are several ways for measuring and assessing pain, which will be described below. The objective assessment of pain is not always effective and safe as the patient often confuses emotions and other factors with what he or she feels or believes and thus makes it difficult to assess the effect pain has on patients' health.

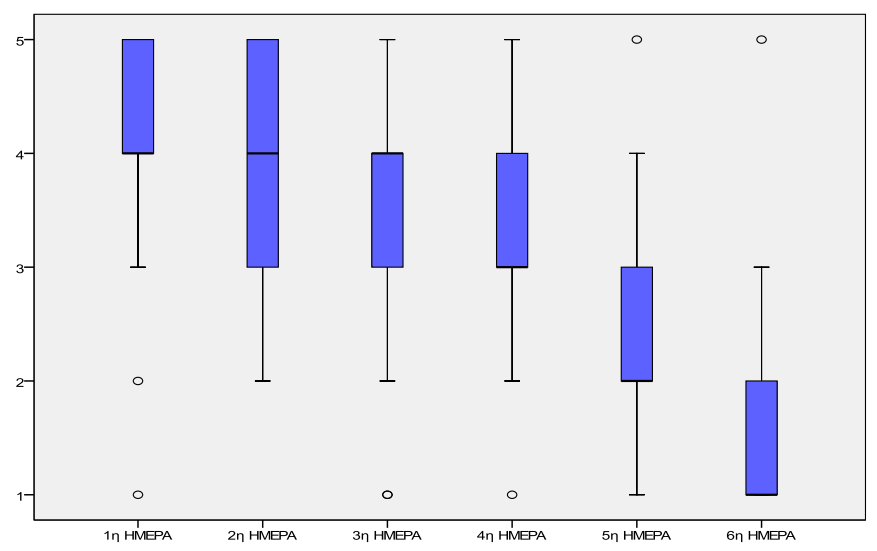

Figure 1. Box-plot of progression of pain intensity during the 6 postoperative days

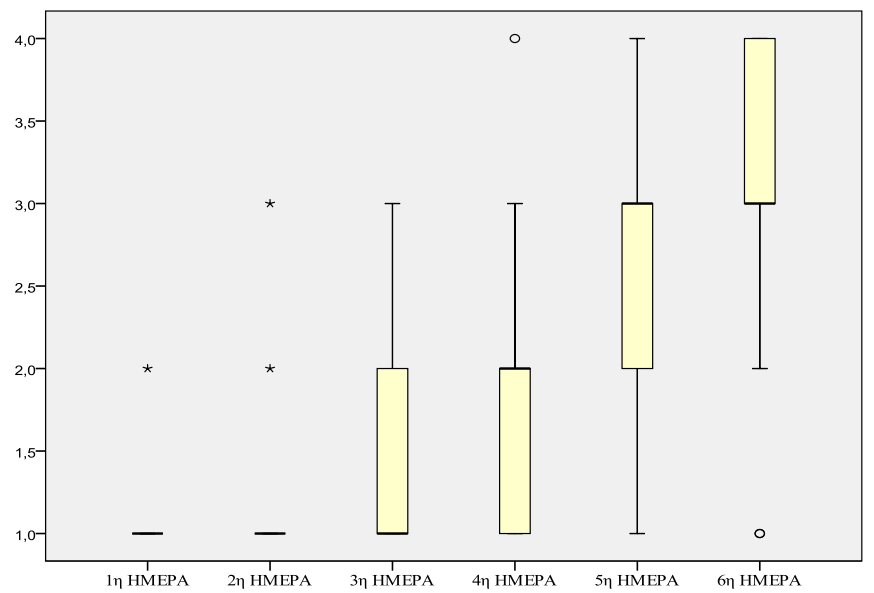

Figure 2. Box-Plot pain fluctuation in the type of pain experience by the sample

i. Scale of words - (Verbal Descriptor Scale) Five descriptive words are usually used: moderate, disturbing, agonizing, terrible, unstable pain and the patient selects and characterizes his condition according to pain intensity with one of them [13]. The method is not considered reliable and is mainly used in low educational level patients.

ii. Optical analogue Scale - Numeric Rating Scale and Visual Analog Scale are an optical or numeric scale respectively, with a score of 0 indicating no pain to 5 or 10 where the pain shows the maximum intensity [14]. These scales are considered a simple and easily comprehensible method.

iii. Table with facemask - (continuum of smiling to crying faces) it is mainly used in children and adults of low educational level [15].

iv. Pain Diary involves a continuous recording of the situation and a description of the pain elements experienced by the patient. In a personal calendar, the patient writes using a score of 0 to 10 per hour, the date the pain was experienced, the duration and location, other symptoms experienced as well as medications received. The purpose of this scale is to monitor the course of the pain over time [13].

v. Questionnaire MPQ (The McGill Pain Questionnaire) It was developed in 1975 by Melzack and Torgerson to measure pain. Its extensive format consists of 78 parameters where the patient is required to grade them while the short form of the same questionnaire consists of 15 parameters, with an overall assessment of pain intensity with a score of 0-6 [16].

vi. Minnesota Multiphasic Personality Inventory, MMPI. It evaluates pain where the nurse communicates with the patient and discusses issues related to mental status, social, family, professional and financial issues [17]. It is considered an objective method however it requires the nurse to have experience, time and good communication skills.

vii. BSAERs- Brain Stem Acoustic Evoked Responses, is a neurophysiological examination that records the brain's response to external stimuli, detecting the reactions of acoustic pathways after repeated acoustic stimulation [18].

viii. SSERs- Somatosensory Evoked Potentials, is a neurophysiological examination by which sensory pathway reaction is detected after repeated irritation of the peripheral sensory nerves [19].

ix. Measurement of behavioral pain, it is a technique that evaluates patients behavior experiencing pain. It is commonly used in neonates, 
children, and patients with difficulties communicating and adults with mental health issues. The most common scales are COMFORT, NIPS, CHIPPS and OPS. The aim is to record the intensity and type of pain (at rest, movement) [3].

\section{Thoracic surgery operations}

Chest surgery requires a careful pre-operative assessment of the patient, and two major goals must be met. The first objective is to assess the morbidity and the risks of an intervention both short and long term [20]. The second is to identify specific factors or risks that may threaten the expected outcome of a surgical procedure [21].

The type of interventions and the anesthesia administered are of particular importance for the prevention of the development of postoperative respiratory complications. In particular, patients that have had thoracic surgery have an increased risk of developing atherosclerosis, pneumonia, bronchitis even severe respiratory failure [22].

The type of incision performed during thoracic surgery varies from patient to patient, but generally, two types are used.

Open access, in which surgery is performed through an incision in the chest wall and the thoracoscopic access is gained for VATS (video assisted thoracic surgery), through small holes in the chest wall allowing the operation to be performed with the use of video imaging [23]. However, $80 \%$ of thoracic surgical procedures are performed via open thoracotomy.

\section{Postoperative complications}

The most common complications following thoracic procedures affect the respiratory (pneumonia) and cardiothoracic system (arrhythmias). More precisely, atelectasis is a dangerous complication as it causes partial or complete collapse of the alveolar walls of the lung to a large extent. This results in the lungs not expanding and gradually showing signs of inflammation and later fibrosis. The patient exhibits cough, shortness of breath, intense pain, tachycardia and generalized shock [24]. Immediate tests should be performed, such as chest X-ray and blood gases, in order to prevent a decrease in blood saturation levels [25]. Antibiotics, oxygen and electrolytes are administered.

The occurrence of postoperative arrhythmias is not a worrying factor for the patient's health [26]. Symptoms of arrhythmia are mainly palpitations, angina, weakness, and shortness of breath. Antiarrhythmic and / or anticoagulant treatment is administered. Additionally, pulmonary embolism is a potentially fatal condition and requires immediate treatment. It is a challenge for both physicians and nurses because at its initial stage, hemoptysis and shortness of breath are absent and the patients dangerous condition is not easily diagnosed [27].

\section{Instructions for the use of analgesics}

Nurses administer analgesics to patients in order to reduce the experience of pain. It is of great importance that nurses have knowledge of pharmacology, including the dose of the drug, the duration of its analgesic effect and its pharmacokinetics. The appropriate route of drug delivery (peros, IV, IM, etc) is then selected according to the patient's needs. The effectiveness of pain relief is monitored after 15 to 30 minutes and at 1 to 2 hour intervals. The degree and duration of pain relief must be documented, and all necessary information must be recorded in the patient's file [28].

In the event that analgesic medication does not relieve the patients' pain, a new analgesic is administered. Nurses must continue to monitor the patient for side effect and be prepared to address these issues it they arise [29]. Patients' psychological support pre-operatively is important, since it could potentially threaten the expected outcome. When the patient it transferred from the operating room to the Intensive Care Unit, and if no major complication occurs (bleeding or respiratory failure), recovery begins [12,30].

Patient age and gender is also important. Elderly patients should be given special attention concerning the dose of analgesia since preexisting complications such as renal failure may lead to further problems. Research suggests that women need higher doses of analgesics in comparison to men [31].

\section{Clinical pain evaluation}

According to the recommendations of the American Society of Pain-2006, when evaluating post-operative pain, health professionals (medical and nursing staff) should assess the patient's condition at regular intervals. The evaluation should be performed during periods of rest and movement, using specific tools for pain assessment [31].

If the patient complaints of pain after a therapeutic intervention, the level of pain must be re-evaluated, and a detailed record should be obtained. Thus, nurses have an important role through continuous patient care to ensure a thorough evaluation with the use of available assessment tools, in order to achieve postoperative pain relief [32]. The aim of postoperative pain assessment is to create a personalized care plan for the patient and then follow specific steps to address the present symptom and ultimately relieve it. Care planning is used collectively by medical and nursing staff. Clinical evaluation of pain begins with an understanding of the condition as an unpleasant patient experience [33].

In addition, characteristics of pain should be determined if it is acute, chronic or intermittent, and its intensity, i.e. mild, moderate, severe or very severe. If the patient is experiencing pain in various parts of the body, the nurse has to rank them in order of priority to deal with. An important factor is the patient's psychological condition and / or other medicines and substances [34].

Despite the advancement in nursing science, effective new drugs and the use of innovative methods of postoperative analgesia, pain continues to be a challenge for nurses [35]. Recent research has shown that more than $50 \%$ of patients report severe pain and inadequate management of postoperative pain [36].

Recent studies conclude that health professionals have poor knowledge of pain management, resulting in under-treatment of pain $[37,38]$. Patients report that nurses caring for patients in surgical departments do not show the appropriate concern regarding pain intensity. Interestingly, inadequate pain relief management is mainly due to lack in nursing education, but also due to patients negative attitudes towards drugs/medicine [39]. Initially, nurses seem to be unaware of the basic principles of pharmacokinetics that result in the administration of medication in inadequate doses or at inappropriate intervals [40]. In addition, nurses do not have experience evaluating, assessing and recording pain properly. As far as the administration of analgesics is concerned, nurses appear to be rather hesitant as they are concerned about possible side effects, which may pose a risk to the patient's health and possible addiction to drugs due to their excessive use.

It is therefore necessary that participation in research projects and continuous education programs for health care professionals 
be constantly enriched on issues they face every day, such as this concerning the management and treatment of pain [41].

Health professionals in many countries around the world have recognized the importance of detailed patient information, while some have been legally obliged. In Greece, the medical practitioner and, more rarely, nurses are considered as the main source of information [42]. One of the rare sources for patient information are books, newsletters and the media [43]. An increasing trend as a source of information is the search on the internet [44].

Internationally, the International Council of Nurses (ICN) points out that teaching the patient and his / her family is part of nursing practice [45]. According to the Code of Nursing Ethics in Greece, patient education is a legal nursing practice [46].

An extensive literature review in medical/nursing journals demonstrated that no research studies have been carried out in relation to the subject of this paper, in Greece or abroad $[47,48]$. To date, an appropriate postoperative pain assessment tool has not yet been developed for patients who have has thoracic surgery. Nurses also appear to be abstaining from the evaluation process either because there are no suitable tools or due to lack of time and appropriate knowledge. The purpose of this research is the-evaluation of post-operative pain experienced by patients who have undergone thoracic surgery.

\section{Methodology}

\section{Method of data collection}

This study used a quantitative approach of a sample of $n=30$ patients who had undergone thoracic surgery. The McGill questionnaire (created by Melzack and Torgerson in 1975- Greek translation was performed by Chapidou and Anagnostou, 2008). Statistical analysis was conducted with the use of the statistical package SPSS 21.

The McGill questionnaire is generally used for the assessment of chronic pain. However, an extensive literature review showed that there is no similar questionnaire for the assessment of postoperative pain, thus, the McGill questionnaire was considered for the purpose of this study as the most appropriate tool to measure patients' pain and intensity. This questionnaire was used in order to quantify the perception of the patients' pain in terms of location, type, and intensity. Of the three available McGill questionnaires, the long form (LF-MPQ) was chosen since it consists of more items and offers more in-depth information for analysis and interpretation.

The first interaction with the patient involved a brief meeting and offered information both verbally and written about the purpose of the study and that their participation was voluntary. Patients were informed that they could withdraw their participation at any time. Once oral and written patient consent was obtained, participants that were able to read and write were included in the study. Then the questionnaire was given with specific instructions for its completion. Data collection concerning pain levels was conducted on a daily basis from the first postoperative day up to the day of discharge for each patient within the surgical department.

Patients were met primarily in the afternoon between 5 and $7 \mathrm{pm}$ since these were the times the patients had not been given any analgesia according to the nursing care plans. The duration of every contact with the patients was 5-15 minutes. A pilot study was carried out using the first five patients in order to assess if there were any problems or misunderstandings with the specific tool (McGill questionnaire). Fortunately, there were no difficulties or misunderstanding with the Greek translation and thus the research officially began.

\section{Sample}

This study used a convenience sample of 30 patients from a hospital in Athens, Greece who had undergone thoracic surgery.

\section{Procedure}

The hospital director as well as the head nurse of the surgical department were contacted and informed about the purpose of this study and ethical approval was obtained.

\section{Statistical analysis}

Descriptive and in-depth parametric and non-parametric tests were used. Due to the small sample size $(n=30)$, nonparametric test was strictly performed maintaining a level of statistical significance $\mathrm{p}<0,05$.

\section{Result}

\section{Demographic characteristics of the sample}

The participants' age ranged from 16 to 88 years and the mean age value was 59 years. The majority of the sample (73.3\%) stated that they had a university educational level while $66.7 \%$ of the sample were man and $33.3 \%$ women. In addition, participants were from Greek islands (40\%), from urban areas (40\%) and $20 \%$ of the patients were from suburban areas. The majority of the participants were smokers (70\%).

\section{Sample characteristics associated with operation type}

The vast majority of the patients that participated in the study (93.3\%) had a close chest drain in situ postoperatively. A thoracotomy was performed at a higher rate $(56.6 \%)$ compared to all other thoracic operations (mini thoracotomy, anterior thoracotomy, posterior thoracotomy). A large number of participants had undergone a lobectomy (36.7\%) while others a biopsy (30.0\%) and a similar (low) percentage had undergone cauterization. Additionally, $90 \%$ of the patients had a surgical procedure under general anesthesia. Regarding pain intensity $53.33 \%$ of the sample expressed the worst feeling of pain as "unbearable", $36.67 \%$ "very strong" while, two participants claimed that their pain was "intense" and one participant was "mild".

\section{Sample characteristics regarding internal pain}

The sensation of internal pain particularly at the site of incision was mention by $43.3 \%$ of the participants while the other participants mention pain at other parts of their bodies (e.g. back, ribs, etc.). It is important to mention, that $10 \%$ of the patients did not complain of internal pain. With the use of Chi square test calculations, the following relations are proven:

1. Patients that have had other types of operations experience internal pain at the incision site

2. Patients who have had a convergence emphysematous blister experience pain at the incision site as well as other parts of their body.

Sample characteristics regarding diagnosis and pain intensity

The data show that $43.3 \%$ of the sample was diagnosed with cancer, $36.7 \%$ with other diseases and $20 \%$ with shortness of breath.

\section{Sample characteristics regarding pain relief}

Almost half of the patients (56.7\%) experienced pain relief with medicine and a combination of other actions such as sleep and rest, 
etc. while, $16.7 \%$ felt pain relief only with medicine and at the same time $26.7 \%$ of the sample claimed that there is nothing to relive their pain. In addition, the data revealed an interesting finding concerning the association between gender and pain relief. More precisely $50 \%$ of the women claimed that they could not get pain relief (in comparison to $15 \%$ of the men) while a higher percentage of men (70\%) claimed that they were relieved with medicine.

\section{Sample characteristics concerning an increase in pain intensity}

It was observed that $70 \%$ of the patients' pain was intensified by all three factors (cough, chest drain, and other), while $30 \%$ of the patients had increased pain due to two factors, (cough and chest drain) as previously mentioned.

\section{Sample characteristics concerning pain intensity}

With the use of the Wilcoxon signed rank test an assessment was made to determine the day with the lowest intensity of pain experienced. Pain intensity depends on the days of recovery postoperatively since there is a reduction in pain as time goes on. This was observed on the $5^{\text {th }}$ towards $6^{\text {th }}$ day where, 24 out of the 30 patients claimed the lowest intensity of pain experienced in comparison to the previous day $\left(4^{\text {th }}\right)$. During the $1^{\text {st }}$ and $2^{\text {nd }}$ day it was observed that the intensity of pain did not show a statistically significant difference $(p>0,05)$. This fact was also proved with the use of Pearson's linear correlation test, where a correlation was evident between pain and the duration of days, with the highest value observes between the 1 st and 2 nd day ( $r: 0,731)$.

Factors associated with pain intensity during six postoperative days:

\section{Based on patients origin}

The intensity of pain during the $6^{\text {th }}$ postoperative day does not correlate with the patients origin $(p>0,05)$.

\section{Based on surgical procedure.}

Using Chi square test demonstrated a dependence between pain intensity and surgical procedure type $(\mathrm{p}<0,05)$. This test showed that patients who had undergone haemostasia, placement of a closed under water drainage system and a convergence emphysematous blister showed increased percentage of "unbearable" pain in comparison to what was expected, while participants that had undergone a lobectomy showed greater percentages of "mild" pain and a smaller percentage "unbearable".

\section{Based on type of analgesia}

The data revealed that pain intensity during the six postoperative days showed a decline for patients who had general anesthesia. However, patients that had local analgesia showed an increase in pain intensity during the first four days postoperatively. Specifically, that pain intensity was relatively stable as the days passed for patients that had local analgesia $(p>0,05)$. It is important to mention that there is no statistical significant correlation between pain intensity and type of analgesia $(p>0,05)$. However, $66.66 \%$ of the participants that had a local anesthetic claimed that their pain was "strong" and "unbearable", in contrast to patients that had a general aesthetic who claimed that their pain levels were lower (42\%).

\section{Based on diagnosis}

Pain intensity during the six postoperative days decreased depending on the patients diagnosis $(\mathrm{p}<0,05)$. The Kruskal Wallis test showed that pain intensity of patients with different diagnoses, does not differ $(p>0,05)$, except for the $2^{\text {nd }}$ postoperative day $(p<0,05)$. This means that there is a difference in pain intensity experienced depending on the patients' diagnosis that day.

\section{Based on the remaining factors}

Pain intensity does not have a statistically significant correlation between factors such as gender, age, education level, chest drain, incision type, location of pain (internal, external) and pain intensity ( $\mathrm{p}>0,05)$.

\section{Sample characteristics in relation to type of pain during the six postoperative days}

Wilcoxon signed rank test was used to assess which day patients felt a change in the type of pain experienced. There was no statistically significant change in the first two days, however, there was a difference the $4^{\text {th }}$ and $5^{\text {th }}$ day where 16 out of 30 patients $(63,3 \%)$, claimed they felt a change it the type of pain they experienced. This was also confirmed with Pearson's linear correlation test, where as a correlation between pain type and days postoperatively was calculated, with the highest factor being observed between day $1^{\text {st }}-2^{\text {nd }}(\mathrm{r}$ : 0.668$)$ and the lowest between day $2^{\text {nd }}-3^{\text {rd }}(\mathrm{r}: 0,457)$.

\section{Sample characteristics in relation to type of pain during six postoperative days in relation to the incision type}

Chi squared test showed that the type of pain experienced by the patients is independent to the incision type $(p>0,05)$. However, patients who had a thoracotomy and anterior thoracotomy experienced greater levels of pain.

\section{Discussion}

Demographic data showed that $70 \%$ of the participants were smokers, and they lived in islands and urban areas of Greece. This finding coincides with the fact that smokers undergo thoracic surgery at a higher rate [30]. The data also revealed that pain location primarily was expresses by the sample at the incision cite $(43,3 \%)$ while the other patients claimed they felt pain in other parts of their body (i.e. back, ribs). All patients were asked if they experienced pain relief and their responses formed three categories. Patients felt relief with the use of medicine and a combination of other actions such as sleep and rest $(56,7 \%), 16,7 \%$ felt pain relief only with the use of medicine, while $26,7 \%$, claimed they felt that their pain could not be relieved at all.

In terms of gender and pain relief, $50 \%$ of the female participants claimed they could not feel pain relief while the majority of men (70\%) stated that they were pain free with the help of medicine and other methods of relaxation. An interesting result was that pain intensity depended on the duration of post-operative days, since there is a reduction in the perception of pain as the post-operative days pass. The first two post-operative days remain an exception, since pain intensity did not show a statistically significant difference and remained the same $(\mathrm{p}>0,05)$.

A reduction was observed the $5^{\text {th }}$ and $6^{\text {th }}$ day, which supports that fact that at least 5 days are needed for postoperative pain to subside. A correlation was observer the $4^{\text {th }}$ and $6^{\text {th }}$ day concerning the patients that were from suburban areas. These patients reported that their pain subsided earlier compared to the patients from other areas of the country (islands and urban origin). In addition, lower pain intensity was found for patient who had a lobectomy in comparison to patient who had haemostasia, closed under water drainage system and a 
convergence emphysematous blister. Also, patients that had undergone general anesthesia reported mild pain in contrast to patient who had local analgesia, who claimed their pain intensity levels were high.

The participants pain intensity and type showed no statistically significant correlation $(\mathrm{p}>0,05)$ with demographic factors such as gender, age, educational level, smoking habit, type of incision, use of a closed under water drainage system, pain relief method, pain manifestation, internal and external pain.

Interestingly, pain type depends of the post-operative recovery day since there is a decrease in intensity and duration of its manifestation as the postoperative days follow from "constant, stable, permanent" in the first two days to "brief, instant, infrequent" and "sudden" on the last day. Last but not least, it is important to mention that the participants from islands expressed their pain as "constant, stable, permanent" in contrast to the participants from suburban areas who described their pain as "brief, instant, infrequent" (mild pain).

\section{Conclusions - Suggestions}

To conclude based on the findings of this study, there is a correlation between the intensity of pain as well as the duration, with the number of days postoperatively. The first two postoperative days are important since the pain is experienced in great intensity and duration. In the following post-operative days, there is a decrease in pain intensity, duration and frequency. After the sixth postoperative days passes patients pain completely subsides feeling "relief" of its negative effect. This means that at least five days are needed for postoperatively pain to subside and allow the patient to feel normal.

Apart from the effect of time on the experience of pain there were other factors that influenced the effect/ relation to pain:

Patients from suburban area showed greater tolerance to pain in contrast to patients for urban and island areas. This knowledge of the patient origin provides the nurse with valuable information since depending on the patients' origin they respond differently to pain and need a different approach in the management of their pain.

Patients that had local analgesia showed increased levels of pain in contrast to those who underwent a procedure with general anesthetic. The first four postoperative days, pain intensity showed stable increased intensity.

Patients that were diagnosed with shortness of breath showed a decline in pain intensity from the $2^{\text {nd }}$ postoperative day.

Pain relief was accomplished with the use of analgesic medication and other ways (sleep, rest).

Further research is needed for these factors since the sample of this study was small as to obtain representative and reliable results for a similar population.

In conclusion, the need for nurses and other health care professionals to be knowledgeable concerning pain management is vital since they are confronted with pain management on a daily basis. Also, knowledge concerning pain physiology, medical and nonmedical interventions of pain relief are also important in helping the multidisciplinary team and especially the nurse in maintain the patients' and his family's quality of life.

In order for this to be accomplished constant and precise assessment of the patients' pain needs to be evaluated with the help of appropriate tools. Since there are no available tools to assess postoperative pain for patients who have undergone thoracic surgery, further research is needed for the development of such a tool that will help nurses evaluate and manage patients' pain. The present research has also revealed that the McGill questionnaire has shown that it can adequately assess postoperative pain in patients with chest surgery.

It seems that further research and continuing education programs for nurses concerning pain management is necessary since innovations and techniques in the health care setting are becoming available aiming to identify the needs for individualized, quality care using a holistic approach.

\section{References}

1. [No authors listed] (1986) Classification of chronic pain. Descriptions of chronic pain syndromes and definitions of pain terms. Prepared by the International Association for the Study of Pain, Subcommittee on Taxonomy. Pain Suppl 3: S1-226. [Crossref]

2. Takeda A, Martin N, Taylor RS, Taylor SJ (2019) Disease management interventions for heart failure. Cochrane Database Syst Rev 1: CD002752. [Crossref]

3. Sarakatsianou X (2012) The assessment and treatment of postoperative pain. Vima tou Asklipiou 11:15-23.

4. Fornasari D (2014) Pain pharmacology: focus on opioids. Clin Cases Miner Bone Metab 11: 165-168. [Crossref]

5. Woolf CJ, Salter MW (2000) Neuronal plasticity: increasing the gain in pain. Science 288: 1765-1769. [Crossref]

6. Yin X, Ye L, Zhao L, Li L, Song J (2014) Early versus delayed postoperative oral hydration after general anesthesia: a prospective randomized trial. Int J Clin Exp Med 7: 3491-3496. [Crossref]

7. Kumarasinghe G, Lavee O, Parker A, Nivison-Smith I, Milliken S, et al. (2015) Posttransplant lymphoproliferative disease in heart and lung transplantation: defining risk and prognostic factors. J Heart Lung Transplant 11:1. [Crossref]

8. Pipanmekaporn $\mathrm{Y}$, Punjasawadwong $\mathrm{S}$, Charuluxananan $\mathrm{W}$, Lapisatepun $\mathrm{P}$, Bunburaphong J, et al. (2014) Incidence of and risk factors for cardiovascular complications after thoracic surgery for noncancerous lesions. $J$ Cardiothorac Vasc Anesth 28: 948-953. [Crossref]

9. Reilly JJ Jr (1997) Preoperative and postoperative care of standard and high-risk surgical patients. Hematol Oncol Clin North Am 11: 449-459. [Crossref]

10. Yalcin NG, Choong CK, Eizenberg N (2013) Anatomy and pathophysiology of the pleura and pleural space. Thorac Surg Clin 23: 1-10.[Crossref]

11. Harris M, Chung F (2013) Complications of general anesthesia. Anesthes clin plastic surg 40: 503-513.

12. Markewitz A, Trummer G, Pilarczyk K (2014) Status of cardiac surgical intensive care medicine in Germany: a report on behalf of the German Society for Thoracic and Cardiovascular Surgery. Thorac Cardiovasc Surg 62: 536-542. [Crossref]

13. Hawker G, Mian S, Kendzerska T, French M (2011) Measures of adult pain: Visual Analog Scale for Pain (VAS Pain), Numeric Rating Scale for Pain (NRS Pain), McGil Pain Questionnaire (MPQ), Short-Form McGill Pain Questionnaire (SF-MPQ), Chronic Pain Grade Scale (CPGS), Short Form-36 Bodily Pain Scale (SF-36 BPS), and Measure of Intermittent and Constant Osteoarthritis Pain (ICOAP). Arthritis Care Res 11: 240-252. [Crossref]

14. Koo BS, Jung MJ, Lee JH, Jin HC, Lee JS, et al. (2015) A pilot study of the correlation between the numeric rating scale used to evaluate "geop" and questionnaires on pain perception. Korean J Pain 28: 32-38. [Crossref]

15. Dworkin RH, Turk DC, Revicki DA, Harding G, Coyne KS, et al. (2009) Development and initial validation of an expanded and revised version of the Short-form McGill Pain Questionnaire (SF-MPQ-2). Pain 144: 35-42. [Crossref]

16. Melzack R (2005) The McGill pain questionnaire: from description to measurement. Anesthesiology 103: 199-202. [Crossref]

17. Tarescavage A, Corey D, Gupton H, Ben-Porath Y (2014) Criterion validity and practical utility of the minnesota multiphasic personality inventory-2-restructured form (mmpi-2-rf) in assessments of police officer candidates. J Pers Assess 97: 382-394. [Crossref]

18. Darrow K, Slama M, Kozin E, Owoc M, Hancock K, et al. (2014) Optogenetic stimulation of the cochlear nucleus using channelrhodopsin-2 evokes activity in the central auditory pathway. Brain Res 1599: 44-56. [Crossref] 
19. Ulu-Kilic O, Parkan S, Ersoy D (2013) Outbreak of postoperative empyema caused by serratia marcescens in a thoracic surgery unit. J Hosp Infect 85:165-242. [Crossref]

20. Pogatzki-Zahn E, Kutschar P, Nestler N, Osterbrink J (2015) A Prospective Multicentre Study to Improve Postoperative Pain: Identification of Potentialities and Problems. PLoS One 10: e0143508. [Crossref]

21. Giummarra MJ, Gibson SJ, Georgiou-Karistianis N, Bradshaw JL (2007) Centra mechanisms in phantom limb perception: the past, present and future. Brain Res Rev 54: 219-232. [Crossref]

22. Sugimura H, Nichols FC, Yang P, Allen MS, Cassivi SD, et al. (2012) Survival after recurrent nonsmall- cell lung cancer after complete pulmonary resection. Ann Thorac Surg 83: 409-418. [Crossref]

23. Merritt W (2007) Thoracoscopy and video-assisted thoracic surgery (VATS). Decision making in Anesthesiology, 4th Edition, Mosby, London. 304-307.

24. Possa S, Braga A, Meira C, Takahama S, Kondo S (2014) Implementation of a guideline for physical therapy in the postoperative period of upper abdominal surgery reduces the incidence of atelectasis and length of hospital stay. Rev Port Pneumol 20: 69-77. [Crossref]

25. Ferraz MB, Quaresma MR, Aquino LR, Atra E, Tugwell P, et al. (1990) Reliability of pain scales in the assessment of literate and illiterate patients with rheumatoid arthritis. J Rheumatol 17: 1022-1024. [Crossref]

26. Walker C (2008) Possible causes of airway, breathing and cardiovascular conditions associated with cardiorespiratory arrest, cardiac arrest and resuscitation. Surgery 26: 60-65.

27. Goldhaber SZ, Morrison RB (2002) Cardiology patient pages. Pulmonary embolism and deep vein thrombosis. Circulation 106: 1436-1438. [Crossref]

28. Barkhouse-Mackeen C, Murphy A (2013) Pharmacology in undergraduate nursing education: innovative strategies for enhancing medication related knowledge, attitudes, skills and behaviours. J Nurs Educ Pract 3: 108-110.

29. Zhiyou Peng, Huiling Li, Chong Zhang, Xiang Qian, Zhiying Feng, Shengmei Zhu (2014) Retrospective Study of Chronic Post-Surgical Pain following Thoracic Surgery: Prevalence, Risk Factors, Incidence of Neuropathic Component, and Impact on Qualify of Life. PLos One 9: 1-9. [Crossref]

30. Bendixen M, Jørgensen OD, Kronborg C, Andersen C, Licht PB (2016) Postoperative pain and quality of life after lobectomy via video-assisted thoracoscopic surgery or anterolateral thoracotomy for early stage lung cancer: a randomized controlled trial. Lancet Oncol 17: 836-44. [Crossref]

31. Dihle A, Helseth B, Kongsgaard U, Paul A, Miaskowski C (2006) Using the American pain society's patient outcome questionnaire to evaluate the quality of postoperative pain management in a sample of Norwegian patients. J Pain 7: 272-280. [Crossref]

32. Gélinas C (2010) Nurses' evaluations of the feasibility and the clinical utility of the Critical-Care Pain Observation Tool. Pain Manag Nurs 11: 115-125. [Crossref]

33. Otsuka M, Yanagisawa M (1990) Pain and neurotransmitters. Cell Mol Neurobiol 10: 293-302. [Crossref]
34. Hirsh AT, Hollingshead NA, Matthias MS, Bair MJ, Kroenke K (2014) The influence of patient sex, provider sex, and sexist attitudes on pain treatment decisions. $J$ Pain 15 : 551-559. [Crossref]

35. Kiekkas P, Gardeli P, Bakalis N, Stefanopoulos N, Adamopoulou K, et al. (2015) Predictors of nurses' knowledge and attitudes toward postoperative pain in Greece. Pain Manag Nurs 16: 2-10. [Crossref]

36. Hanna M, Jean-Pierre P (2014) Postoperative pain and other acute pain syndromes. Practical management of pain, Philadelphia. 271-297.

37. Bjørnnes AK, Parry M, Lie I, Fagerland MW, Watt-Watson J, et al. (2016) Pain experiences of men and women after cardiac surgery. J Clin Nurs 25: 3058-3068. [Crossref]

38. van Dijk JF, Schuurmans MJ, Alblas EE, Kalkman CJ, van Wijck AJ (2017) Postoperative pain: knowledge and beliefs of patients and nurses. J Clin Nurs 26: 35003510. [Crossref]

39. Eriksson K, Wikström L, Fridlund B, Årestedt K, Broström A (2017) Association of pain ratings with the prediction of early physical recovery after general and orthopaedic surgery-A quantitative study with repeated measures. $J$ Adv Nurs 73: 2664-2675. [Crossref]

40. Wilson B (2007) Nurses' knowledge of pain. J Clin Nurs 16:1012-1020. [Crossref]

41. Niraj G, Kelkar A, Kaushik V, Tang Y, Fleet D, et al. (2017) Audit of postoperative pain management after open thoracotomy and the incidence of chronic postthoracotomy pain inmore than 500 patients at a tertiary center. J Clin Anesth 36: 174-177. [Crossref]

42. Noulas N, Kouvalakidou A (2012) The confrontation of pain: a historical review. Achaiki Iatriki 31: 72-80.

43. Parker J (2015) Teaching nursing students about chronic pain: the lived experience perspective of nurse educators. J Nurs Edu Practice Intern 5: 56-78.

44. Polikandrioti (2011) Patients' needs with heart diseases. To Vima tou Asklipiou 9: 380479 .

45. Krokmyrdal KA, Andeneas R (2015) Nurses' competence in pain management in patients with opioid addiction: a cross-sectional survey study. Nurse Educ Today 35: 789-794. [Crossref]

46. Bryant-Lukosius D, Di Censo A, Browne G, Pinelli J (2004) Advanced practice nursing roles: development, implementation and evaluation. $J$ Adv Nurs 48: 519-529. [Crossref]

47. Wikstrom L, Eriksson K, Fridlund B, Arestedt K and Brostrom A (2016) Healthcare professionals' descriptions of care experiences and actions when assessing postoperative pain - a critical incident technique analysis. Scand J Caring Sci 30: 802-812. [Crossref]

48. Yin HH, Tse MM, Wong FK (2011) Postoperative pain experience and barriers to pain management in Chinese adult patients undergoing thoracic surgery. $J$ Clin Nurs 21 : 1232-1243. [Crossref]

Copyright: (C2018 Bakalis NA. This is an open-access article distributed under the terms of the Creative Commons Attribution License, which permits unrestricted use, distribution, and reproduction in any medium, provided the original author and source are credited. 